\title{
Association of HLA-Aw31 and HLA-DR1 with adult rheumatoid arthritis
}

\author{
B. SCHIFF, Y. MIZRACHI, S. ORGAD, M. YARON, ANDE. GAZIT \\ From the Rheumatology Service, Ichilov Hospital, and the Tissue Typing Laboratory, Chaim Sheba Medical \\ Center, Tel-Hashomer, Israel
}

SUMMARY Forty-nine Israeli Jewish patients with rheumatoid arthritis (RA) were studied for their HLA A, B, C, DR antigen frequency. A significant increase in HLA Aw31 and HLA DR1 was observed $\left(\mathrm{p}<5 \cdot 10^{-5}\right.$ and $\mathrm{p}<5 \cdot 10^{-3}$ respectively). $45 \%$ of Aw31 positive patients were seronegative for rheumatoid factor, while most HLA DR1 positive individuals were seropositive. DR5 was found to be significantly decreased $\left(\mathrm{p}<5 \cdot 10^{-4}\right)$. Contrary to previous reports, DRw4 was found to be within the range of antigen frequency of the controls $(34.7 \%$ vs. $32 \%)$. It is suggested that in our population of patients Aw31 and DR1 and not DR4 are highly associated with adult onset of RA.

Rheumatoid arthritis (RA) is a diseases with abundant evidence for immunological abnormalities, and it was therefore of interest to look for its associations with the major histocompatibility complex. ${ }^{1}$ In the past, testing for the HLA A and B polymorphisms did not yield any significant associations with $R A,{ }^{2}$ but, when HLA D and DR were described and tested for, it was readily established that adult onset of RA is significantly associated with HLA Dw4 and DR4..$^{3-6}$ These observations were later confirmed by several investigators working collaboratively during the 7 th and 8th International Histocompatibility Workshops. ${ }^{78}$ In familial RA it was later possible to map the susceptibility locus RLA-1 to chromosome 6, centromeric to locus HLA D. ${ }^{9}$

We have observed in the past that our population does not always follow the same HLA and disease association, ${ }^{1011}$ and it seemed important to reevaluate the situation in our RA patients.

\section{Materials and methods}

PATIENTS

Adult Jewish RA patients were selected from our outpatient clinic. They comprised a total of 49 patients, 41 females and 8 males, ranging in age from 50 to 75 years. There were 29 Ashkenazi and 20 non-Ashkenazi Jews. Only those satisfying the criteria for definite or classical RA set by the American Rheumatism Association ${ }^{9}$ were studied. For each

Accepted for publication 16 June 1981.

Correspondence to E. Gazit, MD, Tissue Typing Laboratory, Chaim Sheba Medical Center, Tel-Hashomer 52621, Israel. individual a very detailed questionnaire was filled out. ${ }^{8}$ It listed all the relevant clinical, laboratory, and roentgenologic information.

\section{METHODS}

Peripheral blood lymphocytes were separated on a Ficoll-hypaque density gradient. ${ }^{12}$ HLA ABC tissue typing was performed by the standard 2-stage NIH microlymphocytotoxicity technique. HLA DR typing was performed by the 2-colour fluorescence technique. ${ }^{13}$ The lymphocytes were typed by local and antisera sets which were made available during the 8th International Histocompatibility Workshop. The antisera were defining $20,40,8$ and 10 antigens at HLA loci A, B, C, and DR respectively.

The computerised comparisons between the clinical, roentgenological, laboratory, and HLA typing were made by the $2 \times 2$ table with the Fisher exact test. Linearity and trends in the proportions were analysed by $3 \times 2$ tables. Only comparisons which yielded statistically significant results were listed in the results.

\section{Results}

Comparisons between HLA antigen frequency in the patients and the controls are presented in Table 1. Only those antigens whose frequency significantly deviated from the controls were listed in the Table.

HLA Aw31 and DR1 were both increased. Aw31 frequency was $18.4 \%$ in the total patient group compared with less than $1 \%$ in the control population $\left(p<5 \cdot 10^{-5}\right)$. Similar results were obtained when the 
Table 1 Comparison of the relevant HLA antigens in the $R A$ patients and control population (in percent)

\begin{tabular}{|c|c|c|c|c|c|c|}
\hline \multirow[b]{2}{*}{$\begin{array}{l}\text { HLA } \\
\text { antigen }\end{array}$} & \multicolumn{3}{|l|}{ Patients } & \multicolumn{3}{|l|}{ Control } \\
\hline & $\begin{array}{l}\text { Total } \\
n=49\end{array}$ & $\begin{array}{l}\text { RA Ash- } \\
\text { kenazi } \\
n=29\end{array}$ & $\begin{array}{l}\text { RA non- } \\
\text { Ashkenazi } \\
n=20\end{array}$ & $\begin{array}{l}\text { Total } \\
n=90\end{array}$ & $\begin{array}{l}\text { Ash- } \\
\text { kenazi } \\
n=51\end{array}$ & $\begin{array}{l}\text { Non-Ash- } \\
\text { kenazi } \\
n=39\end{array}$ \\
\hline Aw31 & $18 \cdot 4^{*}$ & $20 \cdot 7$ & $15 \cdot 0$ & 0 & 0 & 0 \\
\hline DR1 & $30 \cdot 6^{* *}$ & $27 \cdot 6$ & $35 \cdot 0$ & $11 \cdot 1$ & $5 \cdot 9$ & $17 \cdot 9$ \\
\hline DR4 & $34 \cdot 7$ & 37.9 & $30 \cdot 0$ & $32 \cdot 0$ & $39 \cdot 2$ & $23 \cdot 0$ \\
\hline DR5 & $16 \cdot 3^{* * *}$ & $3 \cdot 3$ & $20 \cdot 0$ & $46 \cdot 7$ & $47 \cdot 0$ & $46 \cdot 0$ \\
\hline
\end{tabular}

${ }^{*} \mathrm{p}<5 \cdot 10^{-5} ;{ }^{* *} \mathrm{p}<10^{-3} ;{ }^{* * *} \mathrm{p}<10^{-4}$. All comparisons remain significant after the correction made for the number tested alleles at that locus.

Table $22 \times 2$ tables describing significant associations between HLA antigens and clinical or laboratory findings

\begin{tabular}{lcccccl}
\hline & $++^{*}$ & +- & -+ & -- & $p$ (Fisher) & Interpretation \\
\hline $\begin{array}{l}\text { HLA Aw31 and } \\
\text { RF }\end{array}$ & 4 & 5 & 38 & 4 & 0.0050 & Neg. assoc. \\
$\begin{array}{l}\text { HLA Bw35 and } \\
\text { RF }\end{array}$ & 10 & 7 & 32 & 2 & 0.0039 & Neg. assoc. \\
$\begin{array}{l}\text { DR5 and severity } \\
\text { at onset }\end{array}$ & 8 & 3 & 15 & 25 & 0.04 & Pos. assoc. \\
\hline
\end{tabular}

$*++=$ Number of Aw31 positive patients with the factor.

$+-=$ Number of Aw31 positive patients without the factor.

$-+=$ Number of Aw31 negative patients with the factor.

$--=$ Number of Aw31 negative patients without the factor.

patients were subdivided into Ashkenazi and nonAshkenazi (Table 1). Likewise DR1 was found increased in both ethnic groups, $p<0.005$ and $\mathrm{p}<0.01$, in the Ashkenazi and non-Ashkenazi groups respectively.

DRW4, however, was found to be within the same range of the control population (Table 1). DR5 was found significantly decreased, $16.3 \%$ in the total patient group compared with $46.7 \%$ in the control population $\left(\mathrm{p}<5 \cdot 10^{-4}\right)$. Several significant comparisons were obtained in looking for associations between the clinical symptoms, laboratory finding, and the HLA antigens (Table 2). Aw31 and Bw35 were each negatively associated with the presence of the rheumatoid factor $\left(\mathrm{p}<5 \cdot 10^{-3}\right.$ and $\mathrm{p}<4 \cdot 10^{-3}$ respectively). DRw4 was highly associated with prolonged morning stiffness $\left(\mathrm{p}<2 \cdot 10^{-2}\right)$ and DR5 was associated with severe symptoms at onset but favourable response to therapy $\left(\mathrm{p}<4 \cdot 10^{-2}\right.$ and $\left.\mathrm{p}<2 \cdot 10^{-2}\right)$.

\section{Discussion}

It has been suggested in the past that rheumatoid arthritis may have more than one aetiology, and our results tend to support this contention. In our population of RA patients the pattern of HLA association is different from what has been described before. ${ }^{3-6}$ HLA Aw31 and DR1, and not DR4, are significantly associated with RA. The excess of Aw31 among our patients has no matched antigen in the other populations. Increased frequency of DR1 and Aw31 was not due to linkage disequillibrium between these anti- gens, since they were found independently increased $(2 \times 2$ tables for association between DR1 and Aw31 resulted in a $\chi^{2}$ of $3 \cdot 0 ; p=7 \cdot 5 \times 10^{-2}$ ).

$45 \%$ of Aw31 positive RA patients were seronegative, while most DR1 positive individuals were seropositive. It is possible, therefore, that in our population of RA patients 2 subtypes of disease exist: (a) seronegative Aw31 positive; and (b) seropositive DR1 positive. The reduced frequency of DR5 was described also among non-Israeli Jewish patients. ${ }^{8}$ It is noteworthy that this antigen was associated with severe manifestations at onset but with a favourable response to therapy. It seems therefore that the presence of this antigen is related to resistance to the development of the disease and to a better prognosis in those who contracted it.

DR4, when present, was associated with severe clinical symptoms such as prolonged morning stiffness.

In conclusion, our RA patients exhibit a different pattern of HLA association. We could delineate 2 distinct subtypes, Aw31 seronegative and DR1 seropositive. Both subtypes, however, did not vary with respect to the severity of their clinical symptoms or response to therapy. It is possible that the lack of clinical discrimination between these 2 subtypes resulted from the rigorous criteria employed in patient selection in order to eliminate questionable cases.

\section{References}

1 McDevitt H O, Bodmer W F. HL-A, immune response genes and disease. Lancet 1974 ; i: 1269-75.

${ }^{2}$ Brewerton D A, Albert E. Rheumatology. In: Dausset J, Svejgaard A, eds. HLA and Disease. Copenhagen: Munksgaard, 1977: 94-107.

3 Stastny P. Mixed lymphocyte cultures in rheumatoid arthritis. $J$ Clin Invest 1976; 57: 1148-57.

4 Jaraquemada D, Pachoula-Papasteriadis C, Festenstein H, et al. HLA-D and DR determinants in rheumatoid arthritis. Transplant Proc 1979; 11: 1306-8.

5 Stastny P. Association of the B-cell alloantigen DRw4 with rheumatoid arthritis. $N$ Engl J Med 1978; 298: 869-71.

- Husby G, Gran J T, Ostensen M, Johannessen A, Thorsby E. HLA-DRw4 and rheumatoid arthritis. Lancet 1979; i: 549-52.

7 Joint report, Rheumatoid arthritis. In: Bodmer W F, Batchelor J R, Bodmer J G, Festenstein H, Morris P J, eds. Histocompatibility Testing 1977. Copenhagen: Munksgaard, 1977: 218-9.

s Stastny P. Rheumatoid arthritis. In: Terasaki P I, ed. Histocompatibility Testing 1980. Los Angeles: UCLA Press, 1980: 681-86.

- Rossen R D, Brewer E J, Sharp J, Ott J, Templeton J W. Familial rheumatoid arthritis. J Clin Invest 1981; 65: 629-42.

${ }^{10}$ Gazit E, Avigad S, Zfat Z, Efter T, Mizrachi Y, Rotem J. The association of HLA-B8 and childhood coeliac disease in an Israeli population. Israel J Med Sci 1977; 13: 400-4.

11 Gazit E, Sartani A, Mizrachi Y, Ravid M. HLA antigen in Jewish patients with juvenile diabetes mellitus. Diabete Metab 1977; 3: 55-8.

12 Boyum A. Separation of leukocytes from blood and bonemarrow. Scand J Clin Lab 1968; suppl: 97.

${ }^{13}$ van Rood J J, van Leeuwen A, Ploem J S. Simultaneous detection of two cell populations by two colour fluorescence and application to the recognition of B-cell determinants. Nature 1976; 262: 795-7. 